\section{Heterogeneity of respiratory disease in children and young adults with sickle cell disease}

\section{ABSTRACT}

To detect and characterise different phenotypes of respiratory disease in children and young adults with sickle cell disease (SCD), 11 lung function and haematological biomarkers were analysed using k-means cluster analysis in a cohort of 114 subjects with SCD aged between 5 and 27 years. Three clusters were detected: cluster 1 had elevated pulmonary capillary blood volume, mixed obstructive/restrictive lung disease, hypoxia and moderately severe anaemia; cluster 2 were older patients with restrictive lung disease; and cluster 3 were younger patients with obstructive lung disease, elevated serum lactate dehydrogenase and bronchodilator reversibility. These results may inform more personalised management strategies to improve outcomes.

\section{INTRODUCTION}

Sickle cell disease (SCD) is one of the most common inherited disorders worldwide, affecting an estimated 300000 newborns every year. The majority of children with SCD in developed countries will survive to adulthood, but may then suffer multiorgan damage, including pulmonary complications. While lung function abnormalities are common in both children and adults, there is not a consistent picture. Furthermore, the aetiology and clinical consequences of the lung function abnormalities are unclear. It seems likely that the respiratory disease is not homogeneous. ${ }^{1}$ Identification of different phenotypes of respiratory disease may provide a basis to stratify patients with regard to management. Cluster analysis is a method of detecting subgroups within multidimensional (ie, comprising many and/or varied measurements) data sets. ${ }^{2}$ We hypothesised that cluster analysis of respiratory function and haematological biomarkers would reveal different phenotypes in patients with SCD.

\section{METHODS}

\section{Study design}

A secondary analysis of data from children and young adults with sickle cell anaemia (homozygous for sickle cell haemoglobin) and ages ranging from 5 to 27 years was conducted..$^{3-5}$ The participants or their parents (in the case of children) gave informed written consent to take part.

\section{Lung function measurements}

Respiratory system resistance at a frequency of $5 \mathrm{~Hz}\left(\mathrm{R}_{\mathrm{rs} 5}\right)$ was measured, then spirometry $\left(\mathrm{FEV}_{1}\right.$ : vital capacity $\left.(\mathrm{VC})\right)$, static lung volumes using whole-body plethysmography (total lung capacity (TLC)) and gas transfer for carbon monoxide (DLCO) were assessed according to the American Thoracic Society/European Thoracic Society criteria. ${ }^{6-8}$ The transfer factor for nitric oxide was obtained by the addition of $40 \mathrm{ppm}$ nitric oxide to the inspired gas mixture prior to commencing the single-breath DLCO measurement and used to estimate the pulmonary capillary blood volume (PCBV). ${ }^{3}$ Arterial oxygen saturation $\left(\mathrm{SpO}_{2}\right)$ was measured using pulse oximetry (Masimo Radical 7, Masimo, California, USA) (see online supplementary file).

\section{Haematological data and SCD complications}

The haemoglobin $(\mathrm{Hb})$ concentrations, lactate dehydrogenase (LDH) levels, reticulocyte percentage (reticulocyte\%) and white cell counts (WCC) were obtained from routine blood tests undertaken within 3 months of lung function testing. The medical records were reviewed and an acute chest syndrome (ACS) episode was diagnosed if the child had suffered chest pain, dyspnoea and fever, together

Table 1 Subject characteristics by cluster

\begin{tabular}{|c|c|c|c|c|}
\hline & Cluster $1(n=14)$ & Cluster $2(n=55)$ & Cluster $3(n=45)$ & $\mathbf{P}$ \\
\hline $\mathrm{FEV}_{1}: \mathrm{VC}^{*}$ & $92.4(88.05-100.9)$ & $97.3(91.1-102.6)$ & 90.7 (85.9-96.2) & 0.002 \\
\hline $\mathrm{R}_{\mathrm{rs} 5}{ }^{*}$ & $165.8(140.8-186.5)$ & $131.6(112.9-160.3)$ & $133.4(110.2-153.6)$ & 0.020 \\
\hline $\mathrm{TLC}^{*}$ & $84.8(82.2-86.8)$ & $85.6(77.4-91.6)$ & 94.1 (85.7-99.6) & 0.003 \\
\hline DLCO* & $98.1(92.5-106.2)$ & $77.8(72.2-83.8)$ & $96.6(88.9-108.3)$ & $<0.0001$ \\
\hline PCBV (mL/L) & $44.9(41.4-47.0)$ & $21.1(17.9-23.5)$ & $26.4(23.4-29.7)$ & $<0.0001$ \\
\hline$(\mathrm{Hb})(\mathrm{g} / \mathrm{dL})$ & $8.2(7.4-8.9)$ & $9.9(8.7-10.8)$ & $8.4(5.7-9.2)$ & $<0.0001$ \\
\hline $\mathrm{SpO}_{2}(\%)$ & $95.8(95.0-97.8)$ & $97.0(95.8-99.0)$ & $95.5(93.0-98.0)$ & 0.0327 \\
\hline LDH (IU/L) & $495(441-622)$ & 399.5 (303.5-474.8) & $639(542-732.0)$ & $<0.0001$ \\
\hline WCC $\left(\times 10^{9} / L\right)$ & $10.7(10.3-12.4)$ & $9.2(7.3-10.8)$ & $11.0(8.8-12.3)$ & 0.015 \\
\hline Reticulocyte\% & $12.7(10.6-14.2)$ & $8.5(6.5-10.5)$ & $10.4(7.7-12.8)$ & 0.018 \\
\hline Age (years) & $14.2(10.3-17.0)$ & $17.5(13.3-21.6)$ & $11.3(9.0-14.5)$ & $<0.0001$ \\
\hline$\%$ Obstructive & 0 & 9.1 & 26.7 & 0.027 \\
\hline$\%$ Restrictivet & 14 & 29.1 & 4.4 & 0.023 \\
\hline$\%$ Mixed $t$ & 21 & 5.5 & 4.4 & 0.028 \\
\hline ACS evert & 35.7 & 33.3 & 33.3 & 0.9231 \\
\hline BDR \%† & 7.1 & 2.0 & 15.6 & 0.0338 \\
\hline \% Hydroxyurea & 14.3 & 10.9 & 15.6 & 0.7358 \\
\hline$\%$ Transfusion & 7.1 & 20.0 & 31.1 & 0.1633 \\
\hline
\end{tabular}

* Lung function tests are expressed as the percentage predicted for age and/or height.

tsupplementary data not used in the clustering.

ACS, acute chest syndrome; BDR, bronchodilator reversibility; DLCO, gas transfer for carbon monoxide; Hb, haemoglobin; LDH, lactate dehydrogenase; PCBV, pulmonary capillary blood volume; $\mathrm{R}_{\mathrm{rs} 5^{\prime}}$, respiratory system resistance at a frequency of $5 \mathrm{~Hz} ; \mathrm{SpO}_{2}$, arterial oxygen saturation; TLC, total lung capacity; VC, vital capacity; WCC, white cell counts. 


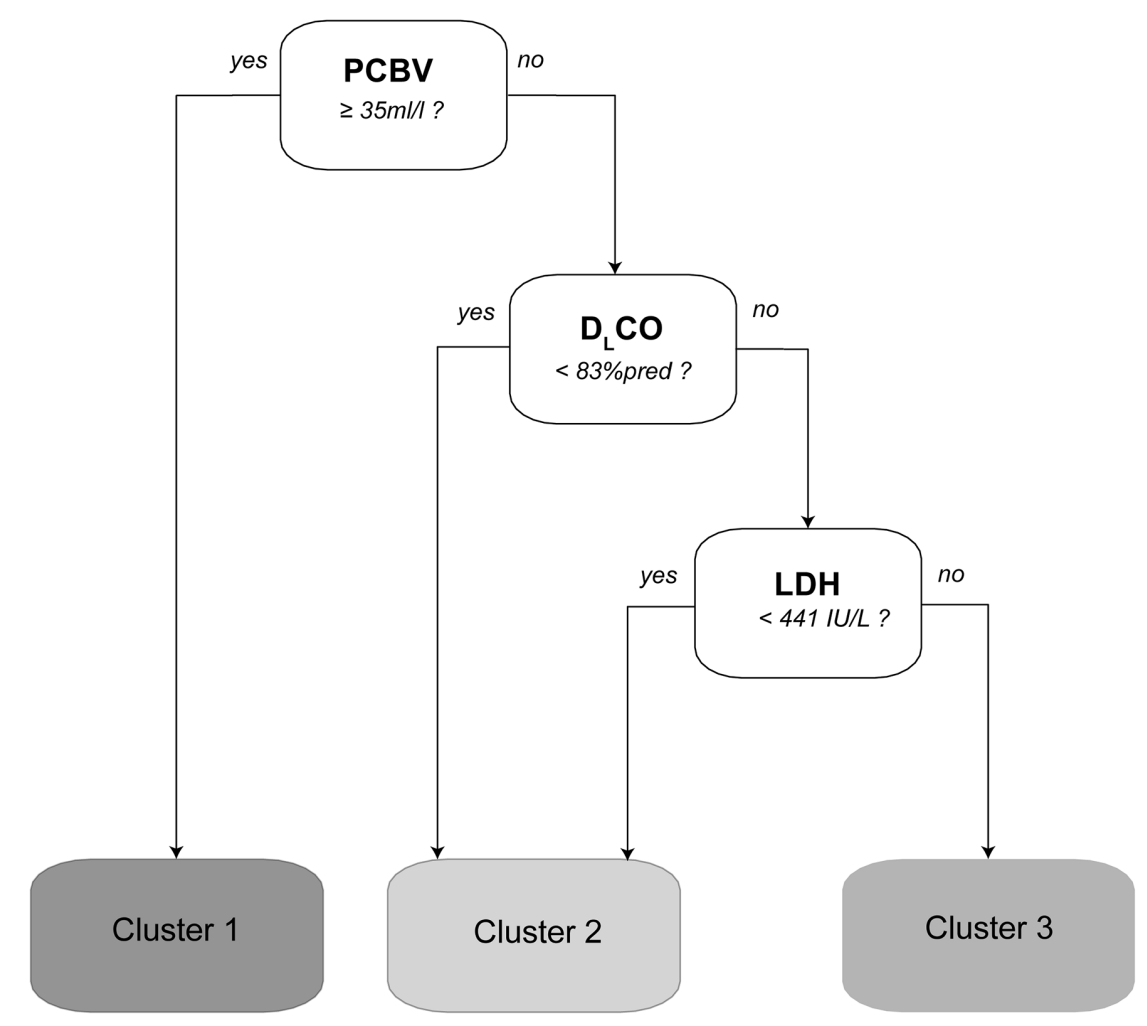

Figure 1 Stratification algorithm to predict cluster membership. DLCO, gas transfer for carbon monoxide; LDH, lactate dehydrogenase; PCBV, pulmonary capillary blood volume.

with a new pulmonary infiltrate on chest radiograph. To determine the impact of cluster membership on future morbidity, the medical records were reviewed for the period subsequent to the lung function testing, and the occurrence of individual ACS episodes and non-elective hospital admissions were recorded and expressed as events/year.

\section{Statistical analysis}

Variables included in the cluster analysis were $\mathrm{FEV}_{1}$ :VC, TLC, $\mathrm{R}_{\mathrm{rs}}$, DLCO, PCBV, $(\mathrm{Hb}), \mathrm{SpO}_{2}, \mathrm{LDH}, \mathrm{WCC}$, reticulocyte\% and age at time of testing. The number of clusters was selected using the criterion-for-clustering function (CritCF) index, ${ }^{9}$ which ranks partitions comprising different numbers of clusters; a higher CritCF indicates a better clustering.

\section{RESULTS}

Data from 114 patients with complete lung function results and a median age of 14.5 (5.0-27.1) years were analysed (see online supplementary table A). A three-cluster solution was found to be optimal (see online supplementary figure S1). The clustering solution was robust under multiple imputations with the same three-cluster partition occurring in $96.4 \%$ of imputed data sets (see online supplementary figure S1). For all lung function and haematological variables, the proportion of patients with obstructive, restrictive or mixed lung function defects and the prevalence of bronchodilator reversibility, but not the proportion taking hydroxyurea, receiving regular transfusions or with a history of ACS episodes, differed significantly between clusters (table 1). Clusters were well separated, with little overlap on a discriminant coordinates plot (see online supplementary figure S2). Physiological profiles for the three clusters are shown graphically (see online supplementary figure $\mathrm{S} 3$ ).

Cluster 1 had the largest proportion with mixed obstructive/restrictive lung disease and both the highest respiratory system resistance and PCBV. Cluster 2 comprised older patients with the highest $\mathrm{FEV}_{1}$ :VC ratio and a low TLC (ie, restrictive pattern), the lowest gas transfer, but the highest $\mathrm{Hb}$. Cluster 3 comprised younger patients with the highest incidence of bronchodilator reversibility and the highest LDH levels (table 1). Cluster 3 has a greater frequency of hospital admissions for vaso-occlusive crises, but not ACS episodes, than clusters 1 and 2 (both $\mathrm{P}<0.05$ ) (see online supplementary file).

A conditional inference tree analysis was performed on the subset of patients assigned to the training set $(\mathrm{n}=85)$. A model using three variables (PCBV, DLCO and $\mathrm{LDH}$ ) (figure 1) was found to be optimal and assigned $90 \%$ of patients from the unseen validation set to the correct cluster. Classification success rates for clusters 1,2 and 3 were $80 \%, 93 \%$ and $90 \%$, respectively.

\section{DISCUSSION}

Analysis of lung function and haematological data detected three distinct clusters in children and young adults with SCD. Cluster 1 had the highest respiratory system resistance and PCBV, which suggest they may have peripheral airways disease mediated by pulmonary vascular engorgement. We speculate that this interaction may arise from direct compression of distal airways by adjacent pulmonary vessels within peribronchial sheaths or from bronchovascular congestion due to elevated pulmonary venous pressure. $\mathrm{Hb}$ levels were significantly higher in cluster 2, which suggests that their restrictive lung disease might be related to increased blood viscosity, leading to impaired microvascular blood flow and an increased likelihood of occult vaso-occlusion in the pulmonary capillary plexus with consequent cumulative lung injury. Cluster 3 had the highest LDH levels and the highest incidence of bronchodilator reversibility. Those findings are consistent with the observation that airway hyper-reactivity, as assessed by methacholine challenge testing, was associated with elevated LDH levels. ${ }^{10}$ Serum LDH, but not reticulocyte count or $\mathrm{Hb}$ concentration, was discriminative for cluster 3 . This may reflect LDH had a greater sensitivity as a marker of haemolysis. LDH, however, is thought to primarily reflect intravascular haemolysis; thus in cluster 3 compared with the other two clusters, perhaps a greater proportion of overall haemolytic activity was occurring in the intravascular compartment.

Conditional tree analysis demonstrated that a subset of the variables could reliably predict cluster membership. This suggests that a method for phenotyping of SCD respiratory subclasses could be based on those biomarkers.

\section{Alan Lunt, ${ }^{1}$ Lucy Mortimer, ${ }^{1}$ David Rees, ${ }^{2}$ Sue Height, ${ }^{2}$ Swee Lay Thein, ${ }^{2,3}$ Anne Greenough ${ }^{1,4}$}

'Division of Asthma, Allergy and Lung Biology, MRC \& Asthma UK Centre in Allergic Mechanisms of Asthma, King's College London, London, UK

${ }^{2}$ Department of Paediatric Haematology, King's College Hospital NHS Foundation Trust, London, UK

${ }^{3}$ Molecular Haematology, Division of Cancer Studies, King's College London, London, UK

${ }^{4}$ NIHR Biomedical Research Centre at Guy's and St Thomas' NHS Foundation Trust and King's College London, London, UK

Correspondence to Professor Anne Greenough, Neonatal Intensive Care Unit, King's College Hospital, Denmark Hill, London SE5 9RS, UK; anne.greenough@kcl.ac.uk 
Acknowledgements We thank Deirdre Gibbons for secretarial assistance.

Contributors $A L$ and $A G$ designed the study. $A L, L M$, $\mathrm{DR}$ and $\mathrm{SH}$ collected the data. AL analysed the data. All authors were involved in the development of the manuscript and approved the final version.

Funding The research was supported by the National Institute for Health Research (NIHR) Biomedical Research Centre based at Guy's and St Thomas' NHS Foundation Trust and King's College London.

Disclaimer The views expressed are those of the author(s) and not necessarily those of the NHS, the NIHR or the Department of Health.

Competing interests None declared.

Ethics approval The studies were approved by King's College Hospital Research Ethics Committee.

Provenance and peer review Not commissioned; externally peer reviewed.

Data sharing statement The data can be open for sharing if required.

(c) Article author(s) (or their employer(s) unless otherwise stated in the text of the article) 2018. All rights reserved. No commercial use is permitted unless otherwise expressly granted.
- Additional material is published online only. To view please visit the journal online (http://dx.doi.org/ 10.1136/thoraxjnl-2017-210206)

\section{D) Check for updates}

To cite Lunt A, Mortimer L, Rees $D$, et al. Thorax 2018;73:575-577.

Received 2 March 2017

Revised 13 November 2017

Accepted 20 November 2017

Published Online First 29 November 2017

\section{Linked}

http://dx.doi.org/10.1136/thoraxjnl-2017-211370

Thorax 2018;73:575-577.

doi:10.1136/thoraxjnl-2017-210206

\section{REFERENCES}

1 Koumbourlis AC. Lung function in sickle cell disease. Paediatr Respir Rev 2014:15:33-7.
2 Wardlaw AJ, Silverman M, Siva R, et al. Multidimensional phenotyping: towards a new taxonomy for airway disease. Clin Exp Allergy 2005;35:1254-62.

3 Wedderburn CJ, Rees D, Height S, et al. Airways obstruction and pulmonary capillary blood volume in children with sickle cell disease. Pediatr Pulmonol 2014:49:716-22.

4 Lunt A, Ahmed N, Rafferty GF, et al. Airway and alveolar nitric oxide production, lung function, and pulmonary blood flow in sickle cell disease. Pediatr Res 2016;79:313-7.

5 Lunt A, McGhee E, Sylvester K, et al. Longitudinal assessment of lung function in children with sickle cell disease. Pediatr Pulmonol 2016;51:717-23.

6 Miller MR, Hankinson J, Brusasco V, et al. Standardisation of spirometry. Eur Respir J 2005;26:319-38.

7 Wanger J, Clausen JL, Coates A, et al. Standardisation of the measurement of lung volumes. Eur Respir J 2005:26:511-22

8 Macintyre N, Crapo RO, Viegi G, et al. Standardisation of the single-breath determination of carbon monoxide uptake in the lung. Eur Respir J 2005;26:720-35.

9 Breaban M, Luchian H. A unifying criterion for unsupervised clustering and feature selection. Pattern Recognit 2011;44:854-65.

10 Field JJ, Stocks J, Kirkham FJ, et al. Airway hyperresponsiveness in children with sickle cell anemia. Chest 2011;139:563-8. 